\title{
A SEALED-ACCELERATOR-TUBE NEUTRON GENERATOR FOR BORON NEUTRON CAPTURE THERAPY APPLICATION
}

\author{
K. N. Leung ${ }^{a}$, Y. Lee ${ }^{a}$, J. M. Verbeke ${ }^{a, b}$, J. Vujic ${ }^{b}$, M. D. Williams ${ }^{a}$, \\ L. K. Wu and N. Zahir ${ }^{\mathrm{a}, \mathrm{b}}$ \\ a Lawrence Berkeley National Laboratory \\ ${ }^{\mathrm{b}}$ Nuclear Engineering Department, University of California, Berkeley \\ Berkeley, CA 94720 \\ USA
}

Abstract

Radio-frequency (RF) driven ion sources are being developed in Lawrence Berkeley National Laboratory (LBNL) for sealed-accelerator-tube neutron generator applications. By using a 2.5$\mathrm{cm}$-diameter RF-driven multicusp source and a computer designed $100 \mathrm{keV}$ accelerator column, peak extractable hydrogen current exceeding $1 \mathrm{~A}$ from a 3-mm-diameter aperture, together with $\mathrm{H}^{+}$yields over $94 \%$ have been achieved. These experimental findings together with recent moderator design will enable one to develop compact $14 \mathrm{MeV}$ neutron generators based on the D-T fusion reaction. In this new neutron generator, the ion source, the accelerator and the target are all housed in a sealed metal container without pumping. With a $120 \mathrm{keV}$ and $1 \mathrm{~A}$ deuteron beam, it is estimated that a treatment time of $\sim 45$ minutes is needed for boron neutron capture therapy.

\section{INTRODUCTION}

The RF-driven multicusp ion source developed at Lawrence Berkeley National Laboratory has found numerous applications ranging from neutral beam injection systems for fusion reactors to particle accelerators, proton therapy machines and ion implantation systems ${ }^{1}$. Such sources are simple to operate, have long lifetimes, high gas efficiencies and provide high density plasmas with high monatomic species yields. These characteristics make the RF-driven ion source a viable candidate for the next generation of compact, high-output, sealed-tube neutron generators, utilizing the fusion of deuterium and tritium, or deuterium and deuterium.

Recently, LBNL has developed a compact, sealed-accelerator-tube neutron generator capable of producing a neutron flux in the range of $10^{9}$ to $10^{10} \mathrm{D}$-T neutrons per second. ${ }^{2-5}$ The ion source, a miniaturized variation of earlier RF-driven multicusp ion sources, is designed to fit within a 5$\mathrm{cm}$-diameter borehole. Typical operating parameters include repetition rates up to $100 \mathrm{pps}$, with pulse widths between 10 and $80 \mu$ s (limited only by the available RF power supply) and source pressure as low as $5 \mathrm{mTorr}$. In this configuration, peak extractable hydrogen current densities exceeding $1 \mathrm{~A} / \mathrm{cm}^{2}$ with $\mathrm{H}^{+}$ion yields over $94 \%$ have been achieved. From this output, a D-T neutron yield of $10^{9}$ neutrons per second can be projected. Simple scaling of the ion source and extraction aperture size could bring the neutron output even higher.

These experimental findings together with recent moderator design ${ }^{6}$ will enable one to develop compact $14 \mathrm{MeV}$ neutron generators based on the D-T fusion reaction. In this new system, the ion source, the accelerator and the target are all housed in a sealed metal container without pumping. With a $120 \mathrm{keV}$ and $1 \mathrm{~A}$ average $\mathrm{D}^{+}$beam current, it is estimated that a treatment time of $\sim 45$ minutes is needed for boron neutron capture therapy $\left(10^{14}\right.$ neutrons $\left./ \mathrm{sec}\right)$. This article describes the design and characteristics of the new neutron generator. 


\section{NEUTRON TUBE DESIGN}

The main components of the sealed D-T neutron tube are the ion source, the $120 \mathrm{kV}$ accelerator column, the water-cooled target and the vacuum system. Figure 1 is a schematic diagram of the sealed D-T neutron generator. It is a scale up version of the compact neutron tube that LBNL has developed. The characteristics of this neutron generator are as follows.

Figure 1: Schematic diagram of the sealed D-T neutron generator.

\subsection{The ion source}

In order to achieve a neutron yield of $10^{14}$ neutrons $/ \mathrm{sec}$, a large 20-cm-diameter multicusp source together with a multi-aperture extraction system to produce an ion beam current of $1 \mathrm{~A}$, accelerated to $120 \mathrm{kV}$, and impinging on a well-cooled target is required. The multicusp generator is a $20-\mathrm{cm}$-diameter cylindrical stainless-steel chamber surrounded with columns of samarium-cobalt magnets. Figure 2 shows a cross-sectional view of the source chamber and the radial plasma density profiles. Apart from an area of about $5 \mathrm{~cm}$ from the chamber wall, the plasma density is very uniform in the central region. Thus, one can form multiple beamlets with good ion optics to enhance the extractable current.

Figure 2: Cross-sectional view of the source chamber and radial plasma density profiles.

If the extraction area is $100 \mathrm{~cm}^{2}$ and assuming $50 \%$ transparency, then the current density at the extraction apertures will be $-20 \mathrm{~mA} / \mathrm{cm}^{2}$. This current density is much lower than other $\mathrm{cw}$ or long pulse ion beam system such as the neutral beam injectors now operated in the tokamak fusion reactors. In order to enhance the monatomic ion species $\mathrm{D}^{+}$or $\mathrm{T}^{+}$, a permanent magnet filter will be installed in the source chamber ${ }^{3}$. The filter configuration can be optimized to produce high $\mathrm{D}^{+}$and $\mathrm{T}^{+}$concentration in the extracted beam which in turn can increase the neutron output.

The plasma is produced by RF induction discharge. In order to deliver RF power to the plasma, a coupler in the form of a multi-turn induction coil is used. The RF antenna coil is fabricated from copper tubing which is normally coated with a thin layer of porcelain for electrical insulation from the conducting plasma. The source is closed-off at one end with a back flange carrying the necessary feedthroughs for the antenna, and a capacitance manometer to monitor source operating pressure. The source will be operated at a background pressure of about $1-2 \mathrm{mTorr}$. We plan to operate the source in a pulsed mode with a $10 \%$ duty factor at a current density of 200 $\mathrm{mA} / \mathrm{cm}^{2}$. This will produce an average beam current of $1 \mathrm{~A}$ on the target. The RF input power for the beam pulse is now higher and the atomic species fraction should improve. The RF power supply is a broad band power amplifier driven at $2 \mathrm{MHz}$ by a signal generator. A pulse generator gates the amplifier so as to generate plasma pulses with durations of $1 \mathrm{~ms}$ and repetition rates of $100 \mathrm{~Hz}$. An impedance matching network connects the RF power supply to the antenna coil. The purpose of this network is to match the nominal $50 \Omega$ output impedance of the RF amplifier to the typical low impedance $(\sim 1 \Omega)$ of the plasma-antenna load.

\subsection{The $120 \mathrm{kV}$ accelerator column}


The beam extraction system which closes off the other end of the ion source chamber, contains three electrodes with multiple 3-mm-diameter apertures. The shape, the separation and the voltage distribution on these electrodes are designed by using the I-GUN computation code. Figure 3 shows the $\mathrm{D}^{+}$ion trajectories for a $200 \mathrm{kV}$ accelerator column. In this arrangement, each beamlet clears all the electrodes. The beamlets expand after they exit from the last electrode and therefore the power can be spread uniformly across the target. The presence of a suppressor electrode will prevent electrons from accelerating back to the source chamber. Thus source and electrode damages caused by high energy backstreaming electrons can be avoided.

Figure $3: \mathrm{D}^{+}$ion trajectories for a $200 \mathrm{kV}$ accelerator column.

\subsection{The water-cooled target}

The target is a water-cooled copper plate covered by a layer of titanium which can absorb deuterium and tritium atoms efficiently. The power density on the target due to the impinging $\mathrm{D}^{+}$ and $\mathrm{T}^{+}$ions is $\sim 1.2 \mathrm{~kW} / \mathrm{cm}^{2}$ which can be easily handled by a modest water flow-rate. In order to maximize the D-T fusion reaction on the target, we plan to operate the multicusp source with a $50 \%-50 \%$ mixture of deuterium and tritium. Our past experience indicates that the target can be loaded by the beam in a very short period of time.

The entire tube will be operated with an ambient pressure of $\sim 2$ mTorr. Low gas pressure is essential for reducing both charge exchange and high-voltage break-down in the accelerator column. In order to control the source operating pressure, some getter pumps will be installed inside the tube. If higher gas pressures are needed, the getter pumps can be heated to release some deuterium and tritium gases. The sealed neutron tube is operated in a safe environment. Since there is no weak component, the lifetime of the tube should be very long. Higher neutron flux can be achieved either by increasing the extraction area or by operating the source with higher discharge power. Epithermal neutrons are needed for BNCT applications. By coupling the sealed neutron tube with a properly designed moderator ${ }^{6}$, one can generate the desired neutron energy spectrum.

\section{ACKNOWLEDGEMENTS}

We would like to thank members of the Plasma and Ion Source Technology Group at LBNL for all the technical assistance. This work is supported by the U.S. Department of Energy under Contract No. DE-AC03-76SF00098.

\section{References}

1. K. N. Leung, Rev. Sci. Instrum., 67, 1302, (1996).

2. L. T. Perkins, P. R. Herz, K. N. Leung and D. Pickard, Rev. Sci. Instrum., 65, 1186, (1996).

3. L. T. Perkins, et.al., Rev. Sci. Instrum., 67, 1057 (19.96).

4. L. T. Perkins, C. M. Celata, K. N. Leung, D. S. Pickard, R. Vilaithong, and M. D. Williams, Proc. of the 1997 Particle Accelerator Conference, Vancouver, Canada.

5. L. T. Perkins et al., Proceedings of the 14th ICAARI, Denton, TX, Nov 1996.

6. J. M. Verbeke, J. Vujic and K. N. Leung (Proc. of this Conference). 


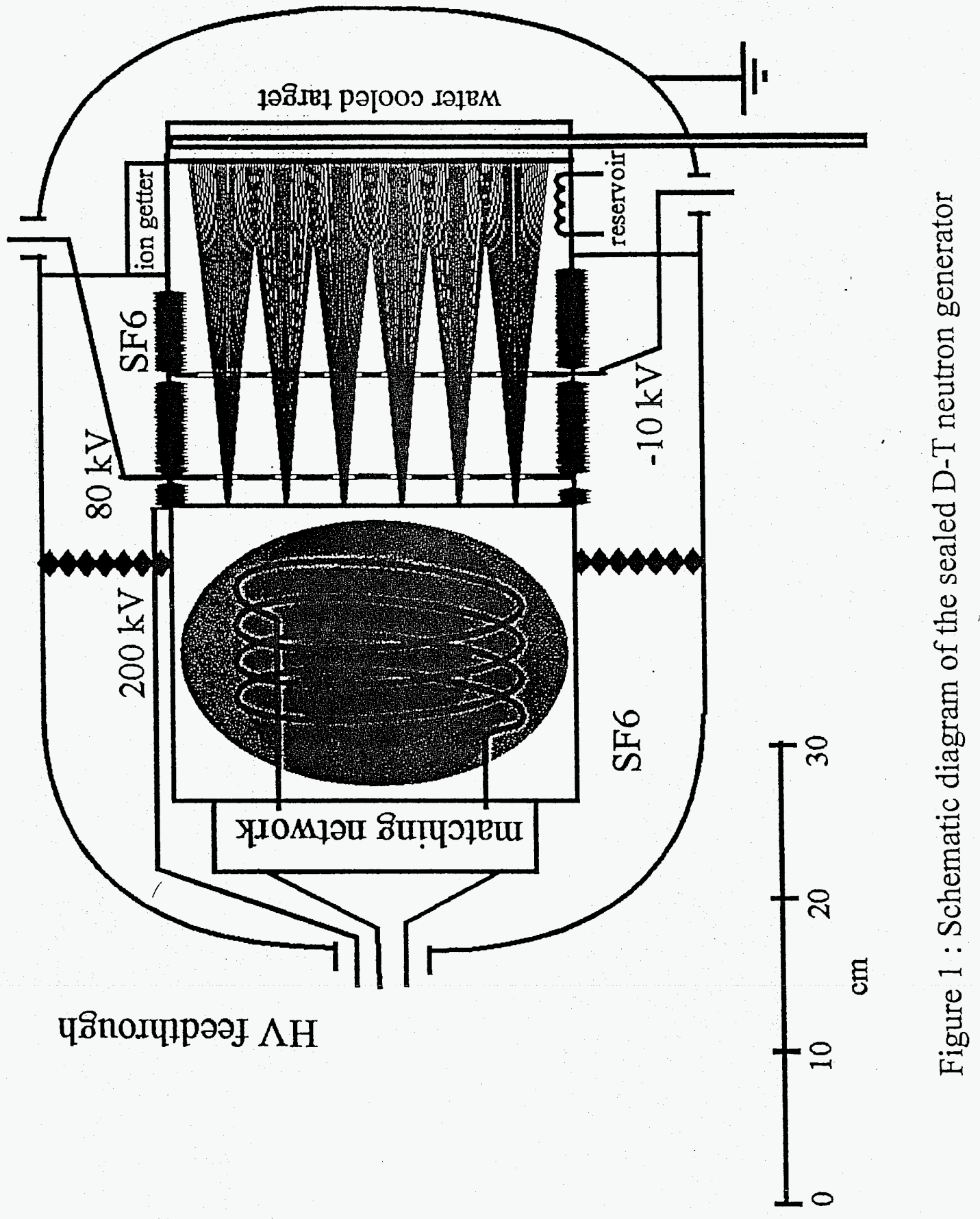




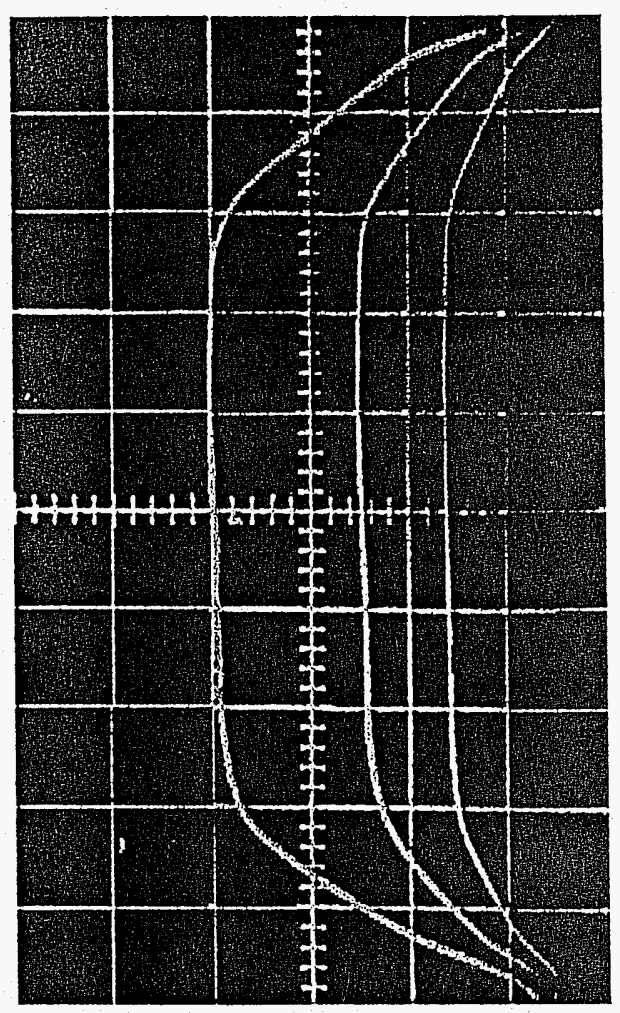

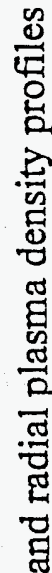

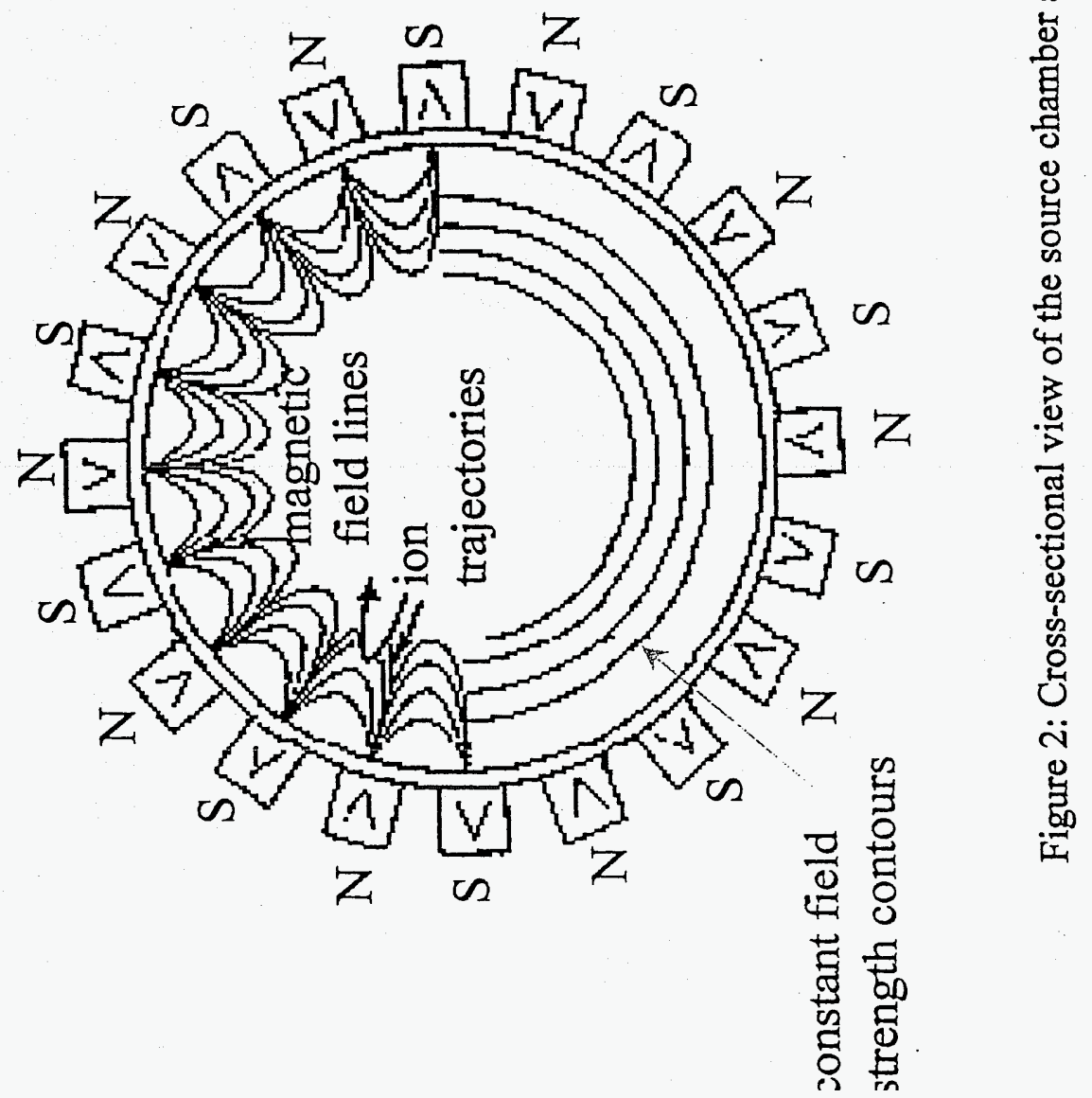




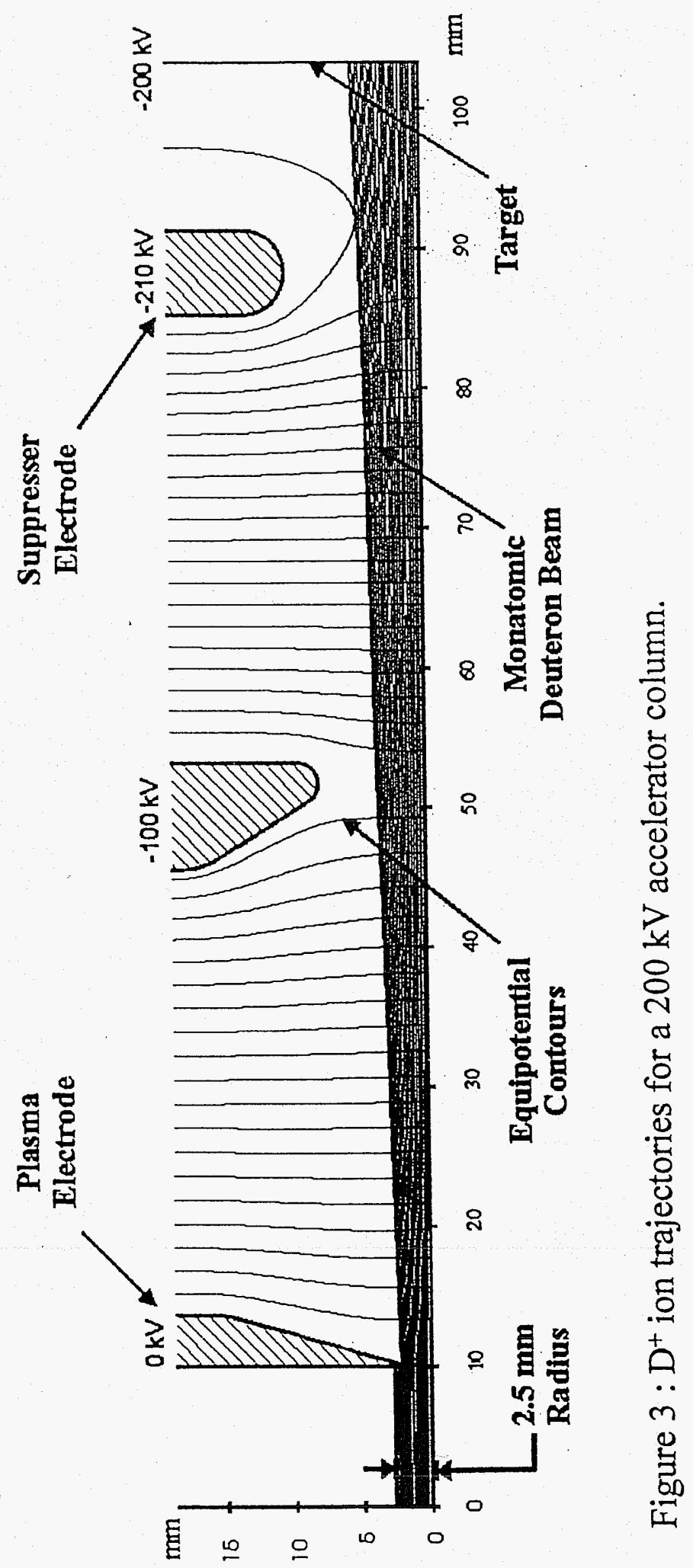

